\title{
Vaginal birth after caesarean section: why and how?
}

\author{
Vidyadhar B. Bangal*, Satyajit Gavhane, Vishesha Yadav, Kunal Aher, Dhruval Bhavsar
}

Department of Obstetrics and Gynecology, Rural Medical College, Loni, Ahmednagar, Maharashtra, India

Received: 08 October 2017

Accepted: 04 November 2017

\section{*Correspondence:}

Dr. Vidyadhar B. Bangal,

E-mail: vbb217@rediffmail.com

Copyright: ( $\odot$ the author(s), publisher and licensee Medip Academy. This is an open-access article distributed under the terms of the Creative Commons Attribution Non-Commercial License, which permits unrestricted non-commercial use, distribution, and reproduction in any medium, provided the original work is properly cited.

\begin{abstract}
Background: With the significant rise in the incidence of primary caesarean section(CS) for various indications, an increasing proportion of the pregnant women coming for antenatal care, report with a history of a previous CS. This necessitates definite need to bring down the caesarean section rate, either by judicious selection of cases for primary caesarean section or by attempting vaginal delivery, following previous caesarean section (VBAC).

Methods: A prospective observational study was conducted to find out the success of VBAC and the common predictive factors leading to successful VBAC. A total of 136 pregnant women with full term pregnancy, having history of previous one lower segment caesarean section and without any other medical and obstetrical complication were enrolled in the study.

Results: Majority of the women (95.59\%) had spontaneous onset of labor. The success of VBAC was 75 percent. The commonest maternal complications were fever $(7.35 \%)$, scar dehiscence $(3.68 \%)$, PPH (1.47\%) and wound infection $(2.21 \%)$. There was significantly higher number of women who had history of previous successful VBAC, had vaginal delivery $(91.67 \%$; $\mathrm{p}=0.038)$.It was observed that the rate of vaginal delivery was significantly high in women with Bishop's score between 10 to $13(94.64 \%)$ compared to 6 to $9(61.25 \%)(p<0.001)$. The baby weight determined by ultrasound scan was significantly associated with mode of delivery $(\mathrm{p}=0.049)$.

Conclusions: Vaginal Birth After Caesarean section is relatively safe, provided it is conducted in carefully selected cases, under constant supervision. Spontaneous onset of labour, good Bishops score and average baby weight were good predictors of successful VBAC.
\end{abstract}

Keywords: Rupture uterus, Scar dehiscence, Trial of labor, Vaginal birth after caesarean section

\section{INTRODUCTION}

With the significant rise in the incidence of primary caesarean sections (CS) for various indications, an increasing proportion of the pregnant women report with a history of a previous CS. These women fall into category of high-risk group due to the risk of a scar rupture. The obstetrician is always in a dilemma regarding the mode of delivery in these cases. Assessment of the individual case with regard to the possibility of a successful VBAC is necessary. The unending dilemma of an obstetrician is about the management of subsequent labour, once the patient has a scar on the uterus. Some suggest an elective CS for such cases, whereas others choose a trial of labour. Many take a middle route, that is, individualization of case.

Previous caesarean section has been found to be the commonest cause of increased caesarean section rate in many parts of the world. ${ }^{1}$ Cragin's dictum "once a caesarean always a caesarean" perpetuates some of the cost of first caesarean section in subsequent pregnancies. ${ }^{2}$ All post caesarean pregnancies do not require repeat cesarean section and a majority of them may have uncomplicated vaginal delivery. ${ }^{3}$ The introduction of lower segment caesarean section resulted in a sound and 
strong scar on the uterus, being capable to hold and safely deliver a subsequent baby by vaginal route. Thus, it is no longer an absolute practice to always opt for caesarean section once a patient underwent caesarean section. However, there is slightly increased risk of uterine scar rupture or scar dehiscence, when vaginal birth after caesarean section is attempted. Therefore, it is now safe to say that 'once a caesarean section, always a hospital delivery'. Present study was conducted to find out the success of VBAC in uncomplicated and carefully selected cases of previous LSCS and to find out the common predictive factors for a successful VBAC.

\section{METHODS}

It was a prospective observational study, conducted for the period of two years from September 2013 to September 2015. A total of 136 pregnant women with full term pregnancy with history of previous one lower segment caesarean section, admitted in a tertiary care teaching hospital, were included in the study. The inclusion criteria were pregnant women with full term gestation in labor with previous LSCS, women with previous one LSCS for non-recurrent indication, women with history of previous one VBAC, Sufficient interdelivery interval ( $>2$ years), pregnant women with no other uterine scars or previous rupture, women with favorable cervix (Bishop's score $\geq 6$ ) were included in the study. Women with high floating head, postdate with unfavorable cervix, more than one previous LSCS, multiple gestational pregnancy, presence of medical or obstetrical complication during pregnancy, moderate and major degree CPD, baby weight $>3.5 \mathrm{~kg}$, fetal malpresentation, scar thickness $<2 \mathrm{~mm}$ on USG and those who were not willing for VBAC were excluded from study.

The study was approved by the Institutional Ethics Committee of Rural Medical College, Loni, Maharashtra prior to the commencement. Pregnant women fulfilling selection criteria were briefed about the nature of the study, details about the VBAC and a written informed consent was obtained.

Demographic data like age, history of previous pregnancy such as indications for LSCS and current pregnancy details including gravida, gestational age, history of previous VBAC were obtained through an interview and recorded on predesigned and pretested proforma. The study investigators examined the participants for their general health and obstetric parameters that is; lie, presentation, position of the fetus and FHR, scar dehiscence, scar tenderness, vaginal examination will be made, and adequacy of pelvis is noted. The weight, height of the participants was recorded using standard methodology. The participants undergoing trial of labour were explained about following aspects.

Patients were kept for spontaneous onset of labour. Patients with postdate pregnancy with borderline Bishops score i.e, 6 were induced with oxytocin $1 \mathrm{mU}$ till adequate contractions. Patients were monitored by hourly recording of vital parameters that is, temperature, pulse, respiration and blood pressure. These women were also monitored for uterine contractions and closely watched for early recognition of scar dehiscence by identifying maternal tachycardia in absence of vaginal bleeding, scar tenderness and fetal heart rate alterations. Progress of labor was monitored with the help of electronic partograph.

The success of VBAC was determined by the percentage of vaginal delivery (including instrumental). Data was analyzed using variables like maternal age, Body mass index, Scar thickness, Bishop's score ( $\geq 6$ to 9 and 10 to 13 ), type of onset of labour, perinatal outcome, maternal complications Neonatal outcome was analyzed in relation to Baby weight APGAR score, NICU admission. The neonates were followed up for NICU admission during their hospital stay and the causes of NICU admission were evaluated.

\section{Statistical analysis}

The categorical data was expressed in terms of frequencies and percentages while continuous data was expressed as mean \pm standard deviation (SD). The association between successful VBAC and various determinants was tested using either chi-square test or Fisher's exact test. A ' $p$ ' value of less than or equal to 0.050 at $95 \%$ confidence interval was considered as statistically significant.

\section{RESULTS}

In the present study, the commonest age group of study participants was 21 to 25 years $(39.71 \%)$ and mean age was $24.04 \pm 3.91$ years. The commonest indication for the LSCS during last pregnancy was fetal distress (44.12\%). A small subset of women $(17.65 \%)$ reported history of previous VBAC. More than half the study population $(58.82 \%)$ were second gravid.

Table 1: Distribution of cases according to the type of labour.

\begin{tabular}{|llll|}
\hline \multirow{2}{*}{ Variables } & Findings & \multicolumn{2}{c|}{ Distribution } \\
\hline Type of & Spontaneous & 130 & 95.59 \\
\hline Labour & Induced & 6 & 4.41 \\
\hline$(n=136)$ & Total & 136 & 100.00 \\
\hline
\end{tabular}

Majority of the women $(67.65 \%)$ were registered for antenatal care. Gestational age between 37 to 40 weeks was noted in $83.83 \%$. General examination finings revealed that in majority of the women $(90.44 \%)$ had body mass index between 19.80 to $26.00 \mathrm{Kg} / \mathrm{m}^{2}$. On obstetric examination, $58.82 \%$ of the women had Bishop's score between 6 to 9 and membranes were present in $79.41 \%$. On ultrasound examination, $62.5 \%$ 
babies had estimated weight between 2.500 to 2.999 Kilogram. In $44.12 \%$ cases, caesarean section scar thickness as assessed by USG ranged between 4.0 to 4.9 $\mathrm{mm}$. Majority of the women $(95.59 \%)$ had spontaneous labour (Table 1).

Seventy five percent women underwent vaginal delivery of which $94(92.16 \%)$ had normal vaginal delivery, while 6 women $(5.88 \%)$ had vacuum delivery and 2 women $(1.96 \%)$ had outlet forceps delivery (Table 2$)$.

Table 2: Distribution of cases according to the mode of delivery.

\begin{tabular}{|llll|}
\hline \multirow{2}{*}{ Variables } & Findings & \multicolumn{2}{l|}{ Distribution } \\
\hline Mode of & Vaginal & 102 & 75.00 \\
delivery & LSCS & 34 & 25.00 \\
\hline (n=136) & Total & 136 & 100.00 \\
\hline Vaginal & Normal & 94 & 92.16 \\
\hline (n=102) & Vacuum & 6 & 5.88 \\
\hline & Forceps & 2 & 1.96 \\
\hline & Total & 102 & 100.00 \\
\hline
\end{tabular}

Twenty five percent women underwent repeat LSCS for scar tenderness (44.12\%) and fetal distress $(20.59 \%)$. Majority of the deliveries resulted in live birth (99.26\%), while perinatal mortality in the form of FSB was noted in $0.74 \%$ (Table 3).

Table 3: Distribution of cases according to the outcome of pregnancy.

\begin{tabular}{|llll|}
\hline \multirow{2}{*}{ Variables } & Findings & \multicolumn{2}{c|}{ Distribution } \\
\hline Pregnancy & Live birth & 135 & 99.26 \\
\hline outcome & FSB & 1 & 0.74 \\
\hline$(n=136)$ & Total & 136 & 100.00 \\
\hline
\end{tabular}

This had happened in an unbooked case due to two tight loops of cord around neck with presence of true knot. Most of the babies weighed between 2.500 to $2.999 \mathrm{Kgs}$ $(60.29 \%)$. Rate of NICU admission was $14.71 \%$ and most of the babies were admitted for observation purpose $(35 \%)$. In this study no association was found between maternal age and mode of delivery $(\mathrm{p}=0.803)$. Significantly higher number of women, who had history of previous VBAC had vaginal delivery (91.67\%; $\mathrm{p}=0.038)$ (Table 4).

Table 4: Association of previous VBAC with mode of delivery.

\begin{tabular}{|c|c|c|c|c|}
\hline \multirow{3}{*}{$\begin{array}{l}\text { Previous } \\
\text { VBAC }\end{array}$} & \multicolumn{4}{|c|}{ Mode of delivery } \\
\hline & \multicolumn{2}{|c|}{ LSCS } & \multicolumn{2}{|c|}{ Vaginal } \\
\hline & No. & Percentage & No. & Percentage \\
\hline Yes & 2 & 8.33 & 22 & 91.67 \\
\hline No & 32 & 28.57 & 80 & 71.43 \\
\hline Total & 34 & 25.00 & 102 & 75.00 \\
\hline
\end{tabular}

Women with spontaneous onset of labour had more success of VBAC than women in which labour was induced (Table 5).

Table 5: Association of type of labour with mode of delivery.

\begin{tabular}{|lllll|}
\hline $\begin{array}{l}\text { Type of } \\
\text { labour }\end{array}$ & LSCS & \multicolumn{3}{l|}{ Vaginal } \\
\hline No. & Percent & No. & Percent \\
\hline Induced & 3 & 50.00 & 3 & 50.00 \\
\hline Spontaneous & 31 & 23.85 & 99 & 76.15 \\
\hline Total & 34 & 25.00 & 102 & 75.00 \\
\hline
\end{tabular}

The rate of vaginal delivery was significantly high in women with Bishop's score between 10 to 13 (94.64\%) compared to 6 to $9(61.25 \%)(\mathrm{p}<0.001)$ (Table 6$)$.

Table 6: Association of Bishop's score with mode of delivery.

\begin{tabular}{|l|llll|}
\hline \multirow{2}{*}{$\begin{array}{l}\text { Bishop's } \\
\text { score }\end{array}$} & \multicolumn{2}{l|}{ Lode of delivery } & \multicolumn{2}{l|}{ Vaginal } \\
\hline 6 to 9 & 31 & 38.75 & 49 & 61.25 \\
\hline 10 to 13 & 3 & 5.36 & 53 & 94.64 \\
\hline Total & 34 & 25.00 & 102 & 75.00 \\
\hline
\end{tabular}

The estimated fetal weight determined by ultrasound scan was significantly associated with mode of delivery $(p=0.049)$. No association was found between scar thickness and mode of delivery $(\mathrm{p}=0.157)$. The commonest maternal complication was fever (7.35\%). Other complications were scar dehiscence (3.68\%), PPH $(1.47 \%)$ and wound infection $(2.21 \%)$. There was no case of cervical tear and lacerations or episiotomy wound gape (Table 7).

Table 7: Distribution of cases according to the complications.

\begin{tabular}{|c|c|c|c|}
\hline \multirow{2}{*}{ Complications } & \multirow{2}{*}{ Findings } & \multicolumn{2}{|c|}{ Distribution (n=136) } \\
\hline & & Number & Percentage \\
\hline \multirow{3}{*}{$\begin{array}{l}\text { Scar } \\
\text { dehiscence }\end{array}$} & Yes & 5 & 3.68 \\
\hline & No & 131 & 96.32 \\
\hline & Total & 136 & 100.00 \\
\hline \multirow{3}{*}{ Fever } & Yes & 10 & 7.35 \\
\hline & No & 126 & 92.65 \\
\hline & Total & 136 & 100.00 \\
\hline \multirow{3}{*}{ PPH } & Yes & 2 & 1.47 \\
\hline & No & 134 & 98.53 \\
\hline & Total & 136 & 100.00 \\
\hline \multirow{3}{*}{$\begin{array}{l}\text { Wound } \\
\text { infection }\end{array}$} & Yes & 3 & 2.21 \\
\hline & No & 133 & 97.79 \\
\hline & Total & 136 & 100.00 \\
\hline
\end{tabular}

Overall, the success rate of VBAC was $75 \%$ and the failure rate of VBAC was $25 \%$ based on pertinent selection criteria and effective monitoring. The common 
predictors of successful VBAC were History of previous VBAC, body mass index, Higher

Bishop's score, non-recurrent indication, spontaneous type of labor and baby weight.

\section{DISCUSSION}

Caesarean section is one of the most commonly performed major surgical procedure. ${ }^{1}$ Worldwide increase in caesarean section (CS) rate during the last three decades has been the cause for concern. Even though, variation exists in rates of caesarean delivery across countries; currently the rate ranges from $10 \%$ to $40 \%{ }^{1,4}$ In Delhi, capital of India, caesarean section (CS) rate in teaching hospitals currently range between 19$35 \%$. This high caesarean section rate has put burden on the economy of nations and individuals and families. ${ }^{5}$

Because of escalating rates of caesarean section, many suggestions were made that vaginal birth after caesarean section (VBAC) might help in reducing the rates of CS. ${ }^{6}$ Because of increased risk of maternal complications with repeat caesarean section and safety of VBAC, trial of labor (TOL) for selected group of patients with previous scar has become a preferred strategy. ${ }^{7}$ Trial of labor is a safe alternative for those patients with a single lower uterine segment scar. Patients who have a recurrent indication for primary caesarean section should be restricted from undergoing a trial of lobour. ${ }^{8}$ A trial of labor is generally not offered after two caesarean section as multiple caesarean sections are associated with many complications like scar integrity and placental complication. ${ }^{9}$

Vaginal birth after cesarean section (VBAC) is associated with short period of hospitalization, less blood loss and fewer transfusions, fewer infections, and fewer thromboembolic events than cesarean delivery. ${ }^{7}$ Several reports have indicated that the absolute risk of uterine rupture, attributable to a trial of labor is about 1 per $1000 \cdot .^{1,4,10} \mathrm{~A}$ successful VBAC has fewer complications than an elective repeat caesarean. ${ }^{11}$ A 60 to $80 \%$ success rate of vaginal birth after previous caesarean section has been reported by many authors if the primary caesarean was done for nonrecurring indications. ${ }^{4,12}$ In the present study ,the success of VBAC was in $75 \%$ cases, which co relates well with the findings of other studies. Mother's choice on mode of delivery is the most important single factor in offering trial of labor. Women's expectations for birth and mode of birth preferences are influenced not only by knowledge of the potential benefits and risks but also demographic, obstetrical and social factors. This knowledge would help while counseling mothers for VBAC. ${ }^{11}$

While there is increased maternal and perinatal morbidity associated with the failure of trial of vaginal birth after cesarean section (VBAC), a successful trial of VBAC reduces the risk of complications in future pregnancies, associated with a repeat cesarean section. Studies in patients attempting VBAC have shown that the highest rate of maternal complications occur in patients, who have a failed attempt at VBAC, intermediate in those who have an elective repeat cesarean section and lowest in those who have a successful VBAC. ${ }^{13}$

Assessment of individual risks and the likelihood of VBAC can help determine appropriate candidates for trial of labor. Screening tools consider the relative effect of multiple factors to predict an individual's likelihood of successful vaginal delivery. ${ }^{14}$ Majority of the scoring systems have used indication of previous cesarean, Bishops score and history of VBAC in their screening tools. Some have used other factors like maternal age, weight, inter-delivery period, estimated fetal weight and history of term/preterm cesarean section. ${ }^{15}$ Although all these factors have been shown to influence VBAC trial outcome they have not achieved statistical significance and hence these factors have not been collectively included in various screening tools.

Hence, the crucial questions are how to reliably predict successful vaginal birth after Caesarean section, and how to determine and quantify the magnitude of the risk of failure that is acceptable to women. Many studies have addressed methods for identifying women at low and high risk of failure of an attempted vaginal birth after a prior caesarean but none of them have resulted in a validated result. ${ }^{7}$ Even those factors found to be associated with successful VBAC, vary from centre to centre. Currently, therefore, there is no single validated tool which holds true for all to predict successful vaginal birth among women with a prior cesarean delivery. ${ }^{7}$ In the present study, the common predictors for successful VBAC were, history of previous successful VBAC, normal body mass index, favorable Bishop's score, spontaneous onset of labor and average baby weight.

\section{CONCLUSION}

Stringent selection criteria and meticulous intra-partum monitoring for VBAC often leads to successful VBAC. It helps in reduction of rate of caesarean section, thereby reducing maternal morbidity associated with repeat LSCS. Proper counselling for trial of scar and evaluation of the case of prior caesarean section has been considered a key method of reducing the caesarean section rate. There is no doubt that a trial of scar is a relatively safe procedure, but it is not risk free and should not be under taken in casual manner. Higher morbidity and health care cost of repeat lower segment caesarean section makes VBAC, a better and safer option in carefully selected women with previous uterine scar.

The success rate observed in the selected population was high $(75 \%)$. The common predictors of successful VBAC found in the present study were history of previous successful VBAC, normal body mass index, Higher Bishop's score, spontaneous onset of labour and average 
baby weight. The success rate of VBAC was independent of maternal age, gravida, antenatal care, presence of membranes, scar thickness and location of placenta. A higher bishops' score is always a promising predictor for VBAC. The present study shows that trial of vaginal delivery in properly selected patients is relatively safe provided trials are conducted in an institution under constant supervision and termination by caesarean section when need arises.

Funding: No funding sources Conflict of interest: None declared

Ethical approval: The study was approved by the Institutional Ethics Committee

\section{REFERENCES}

1. American College of Obstetricians and Gynaecology (ACOG). ACOG Practice Bulletin: vaginal birth after previous caesarean delivery: Clinical management guidelines. Int $\mathbf{J}$ Gynecol Obstet. 2004;54:197-204.

2. Cragin B. Conservatism in Obstetrics. New York Med J. 1916;104:1-3.

3. Khotaba S, Volfson M, Tarazova L, Odeh M, Barenboym R, Fait V et al. Induction of labour in women with previous caesarean section using the double balloon device. Acta Obstet Gynecol Scand. 2001;80:1041-2.

4. Cunnigham F, Leveno K, Bloom S, Spong CY, Dashe J. Williams Obstetrics. 24 ${ }^{\text {th }}$ ed. New York: McGraw-Hills;2010.

5. Sachdeva S, Nanda S, Sachdeva R. Birth audit. J Nat Sci Biol Med. 2013;4(1):155-9.

6. Mafatlal SJ, Narendrabhai MM. Analysis of mode of delivery in women with previous one caesarean section. J Obstet Gynecol India. 2009;59(2):136-9.

7. Birara M, Gebrehiwot Y. Factors associated with success of vaginal birth after one caesarean section (VBAC) at three teaching hospitals in Addis Ababa, Ethiopia: a case control study. BMC Pregnancy Childbirth. 2013;13:31.

8. Stovall TG, Shaver DC, Solomon SK, Anderson GD. Trial of labour in previous caesarean section patients, excluding classical caesarean sections. Obstet Gynecol. 1987;70(5):713-7.

9. Tahseen S, Griffiths M. Vaginal birth after two caesarean sections (VBAC-2)-a systematic review with meta-analysis of success rate and adverse outcomes of VBAC-2 versus VBAC-1 and repeat (third) caesarean section. BJOG. 2010;117(1):5-19.

10. Ugwumadu A. Does the maxim once a caesarean, always a caesarean still holds true? PLoS Med. 2005;2(9):e3053.

11. ACOG Guidelines. Ob-Gyns Issue Less restricitive VBAC guidelines. Washington (DC): American College of Obstetricians and Gynaecologists (ACOG); 2010. Available at https://www.acog.org/About-ACOG/NewsRoom/News-Releases/2010/Ob-Gyns-Issue-LessRestrictive-VBAC-Guidelines

12. Royal College of Obstetricians and Gynaecologists. Birth after previous caesarean section.Green top guideline No. 45, RCOG press. Feb 2007. Available at

https://www.rcog.org.uk/globalassets/documents/gui delines/gtg_45.pdf

13. Landon MB, Hauth JC, Leveno KJ, Spong CY, Leindecker S, Varner MW, et al. Maternal and perinatal outcomes associated with a trial of labour among women with prior caesarean delivery. N Engl J Med. 2004;345:3-8.

14. Cunningham FG, Bangdiwala SI, Brown SS, Dean TM, Frederiksen M, Hogue CR et al. National Institutes of Health Consensus Development Conference Statement: Vaginal Birth After Cesarean Section: New Insights March 8-10, 2010. Obstetric Anesthesia Digest. 2011 Sep 1;31(3):140-2.

15. Narang H, Singhal S, Ravi V. Assessment of factors individually and as a scoring system in predictive screening for VBAC in patients undergoing trial of labour after single previous caesarean section. IOSRJDMS. 2014;13(10):109-15.

Cite this article as: Bangal VB, Gavhane S, Yadav V, Aher K, Bhavsar D. Vaginal birth after caesarean section: why and how?. Int J Reprod Contracept Obstet Gynecol 2017;6:5554-8. 